\title{
Presenting the Architecture of OR E-Courses
}

\section{Cornel Resteanu, Doina Banciu}

National Institute for Research and Development in Informatics, 8-10, Averescu Avenue, 011455, Bucharest 1, ROMANIA resteanu@ici.ro,doina.banciu@ici.ro

Abstract: After a good experience in the e-courses' design, the authors have arrived at the conclusion that such a course is made from a specific part named course's digital content and a general part named course's shell. The first part is represented by the knowledge that must be transferred from teachers to students. The second part, the general one, is represented by the mediator of this transfer. This paper aims at presenting the architecture of an Operation Research e-course by describing the course's digital content as well as the course's shell, both generating an ITC product belonging to the software as a service class.

Keywords: Creativity and Personal Development, Livelong Learning, Enhanced Learning Technology, Information and Communication Technology, Internet Computing, Software as a Service.

\section{Introduction}

In the Creativity and Personal Development (CPD) era, the Lifelong Learning (LLL) concept acquires new meanings with the $e$ courses development in Enhanced Learning Technology (ELT) using Information and Communication Technology (ICT), mostly Internet Computing (IC) tools. Every highly educated person currently learns in his / her social life. Also, one may notice that the available time for learning decreases with age and socio-professional position.

As a consequence of these facts, the courses made by experts, for integral electronic learning, having the Internet as support, which may be used according to a personal schedule, are nowadays the most appropriate. But such a course is very difficult and expensive to realize. Then the main idea is to approach each domain (like mathematics, physics, chemistry, biology, informatics, engineering, pedagogy, etc.) separately and try to design a standard e-course for each of them.

The project named "Excellency Level Tools for Multi-Attribute Decision Making [1, 2] Field's Promotion", belonging to a Romanian research program, aligned to the European program in this domain [3], produced the Multi-Attribute Decision Making (MADM) ecourse with a general shell (GS) named "OR e-courses shell" that can present the digital content (DC) (Figure 1) not only for this very course but for every one presenting the same structure of its knowledge thesaurus (KT).
KTs that have the same structure belong, in the present case, to the Operations Research (OR) domain, containing mathematical programming, graph theory, transport problems, stochastic processes, queuing theory, game theory, decision analysis etc.

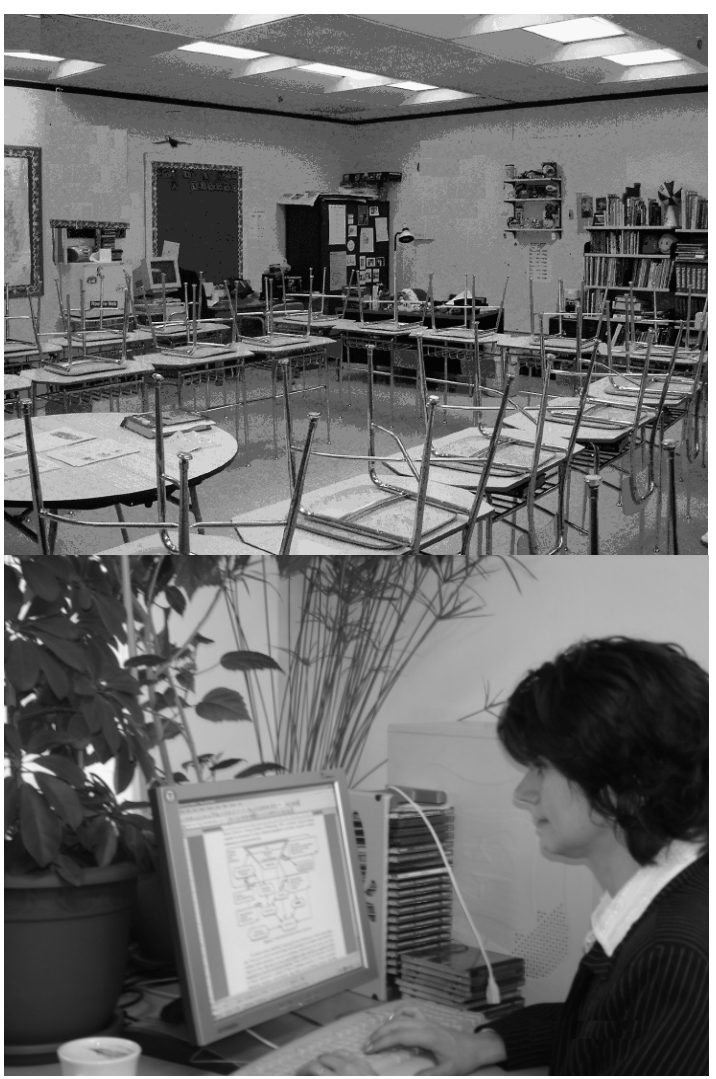

Figure 1. From regular OR learning to continuous individual learning

The e-course, named 'Do learn by yourself $M A D M$ ', will be presented following the general block-scheme used in design (see Figure 2). 
The central role is attributed to the users: administrators, professors, tutors as ecourse's creators, and students / visitors as ecourse's beneficiaries.
The administrators are ITC specialists organized by two levels. The first level contains the head of administrators and the second level contains the rest of administrators.

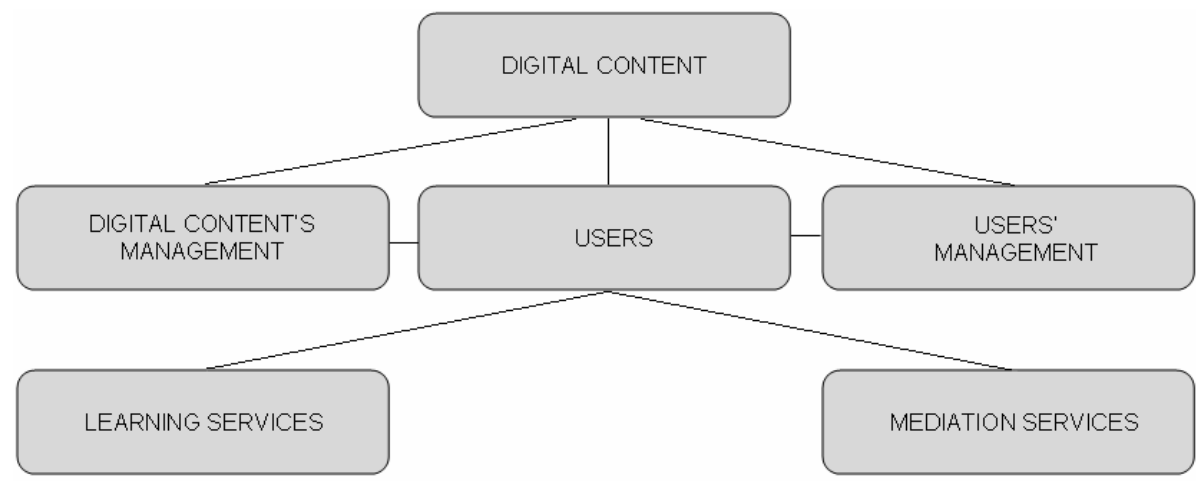

Figure 2. Block scheme for the 'Do learn by yourself $M A D M$ ' e-course

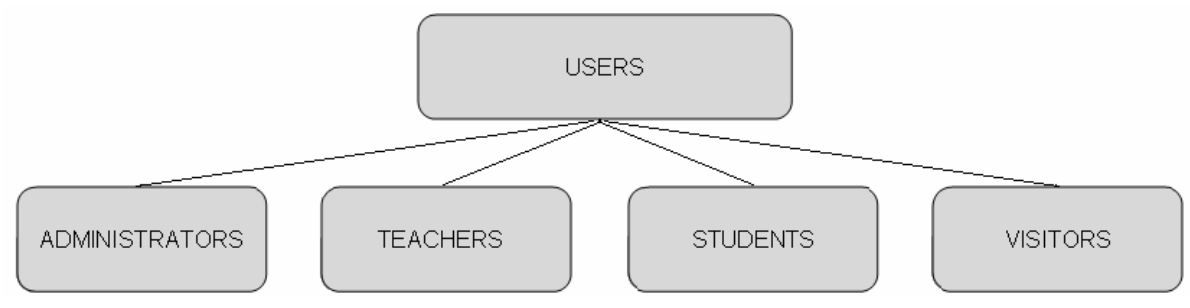

Figure 3. Users' structure

The users have a management module which works on a data base. It provides users' lists and lists linked to students' learning rhythm, exams' situations, interactivity with the ecourse, graduation diploma etc. The digital content has a complex management module which works on a knowledge base. Learning items, as lessons, tests, problems / case studies, most frequent asked questions, bibliography, and additional items, as auto-presentation, users' guide and sensitive help are provided through these management modules.

The services offered to the students are learning services and mediation services that assure the interface with a part of the Internet environment dealing with this electronic course $[4,5,6]$.

\section{E-Course's users}

There are four types of users (see Figure 3), after their role in the system: administrators, teachers, students and visitors.
The head of administrators installs the course's software on the hardware platform, initiating the e-learning service, and grants rights, in the management of e-course, to the rest of administrators.

The teachers are the persons providing all digital content and enriching it along the evolution of e-course. They are experts in the domain which write the course's digital content.

The tutors are the persons which are entitled to answer the students' questions during the learning process. Teachers as well as e-course's graduate students with brilliant results can become tutors with integral rights in helping the students in the assisted learning process.

The students pay the e-course and they are the plenary beneficiaries of it; they run through the modules' lessons and exams and finally graduate.

The visitors do not pay the e-course, they can run through the modules' lessons but they can not take exams and by consequence do not graduate. 


\section{E-Course's Digital Content}

First, DC contains (see Figure 4) a small part dedicated to the e-course auto-presentation, usually a sound film, and a part dedicated to the users' guide, usually a text. Obviously, these are knowledge about knowledge i.e. meta-knowledge (MK).
The difficulty increases for all kinds of KTL with the course modules and with the learning days.

\section{KTV's Presentation}

The KTV (see Figure 6) represents the content for modules exams and graduation exam.

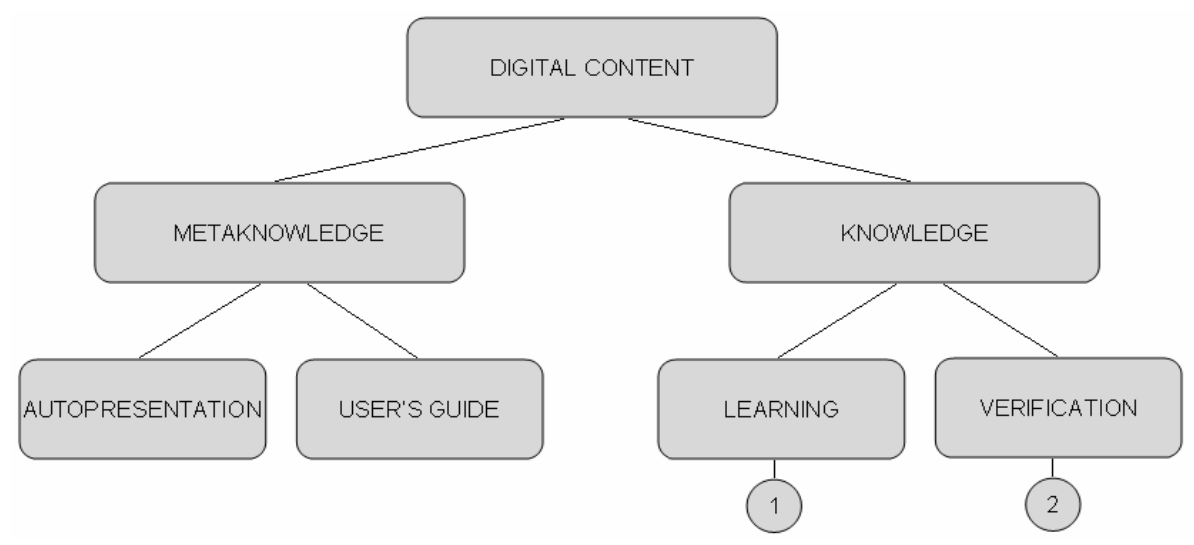

Figure 4. Digital content's structure

Second, DC contains the main part, namely $\mathrm{KT}$, represented by the genuine e-course's knowledge. KT is divided, at its tour, from its functional point of view, into two parts. The first part is the $\mathrm{KT}$ for the learning process (KTL) and the second part is the KT for the verification process (KTV). Both have the same importance in KT, they are balanced and equally contribute to the learning process.

\section{KTL's Presentation}

The KTL (see Figure 5) represents the content for $n$ course modules (in this case 4), each of it containing $m$ learning days (in this case 5). One day offers a lesson (all lessons, as dimension, is balanced, about 6 A4 pages at 12 font size), a set of grill-tests (10 as number) with the correct answer presented and a set of problems / case studies (5 as number) also with the solving presented. For each course module exist, from the very beginning but enriched itself during the course using, the most frequently asked questions (FAQ) (for the beginning 10 as number) and a bibliography. As a consequence, there are hundreds of multiple choice tests and problems / case studies, enough to make the learning process easier.
These two kinds of exams, albeit alike, as content are different. Each learning day, and by consequence, each course module has associated a set of multiple choice tests and a set of problems / case studies. The set of multiple choice tests and the set of problems / case studies for the graduation exam, by types, are from cardinality point of view greater than the previous ones, and also more difficult. If the KTL, in the electronic course, is used as such, the KTV is used for random generation of exams, which must be different from one student to another. The degree of collisions must be very small, and if possible equal to zero.

\section{Example of KT}

The knowledge thesaurus taken as example in this section belongs, obviously, to the MADM e-course. It provides knowledge regarding a basic problem of Decision Theory: the Optimal Choice Problem (OCP) [7]. 


\section{Lessons}

As said before, this electronic course is composed by four modules, each of them comprising five learning days: attributes, and the model expert knowledge [8] expressed through a set of production rules that deal with the potential drawbacks of a MADM model, i.e. syntactic / semantic incorrectness, incredibleness or incompleteness.

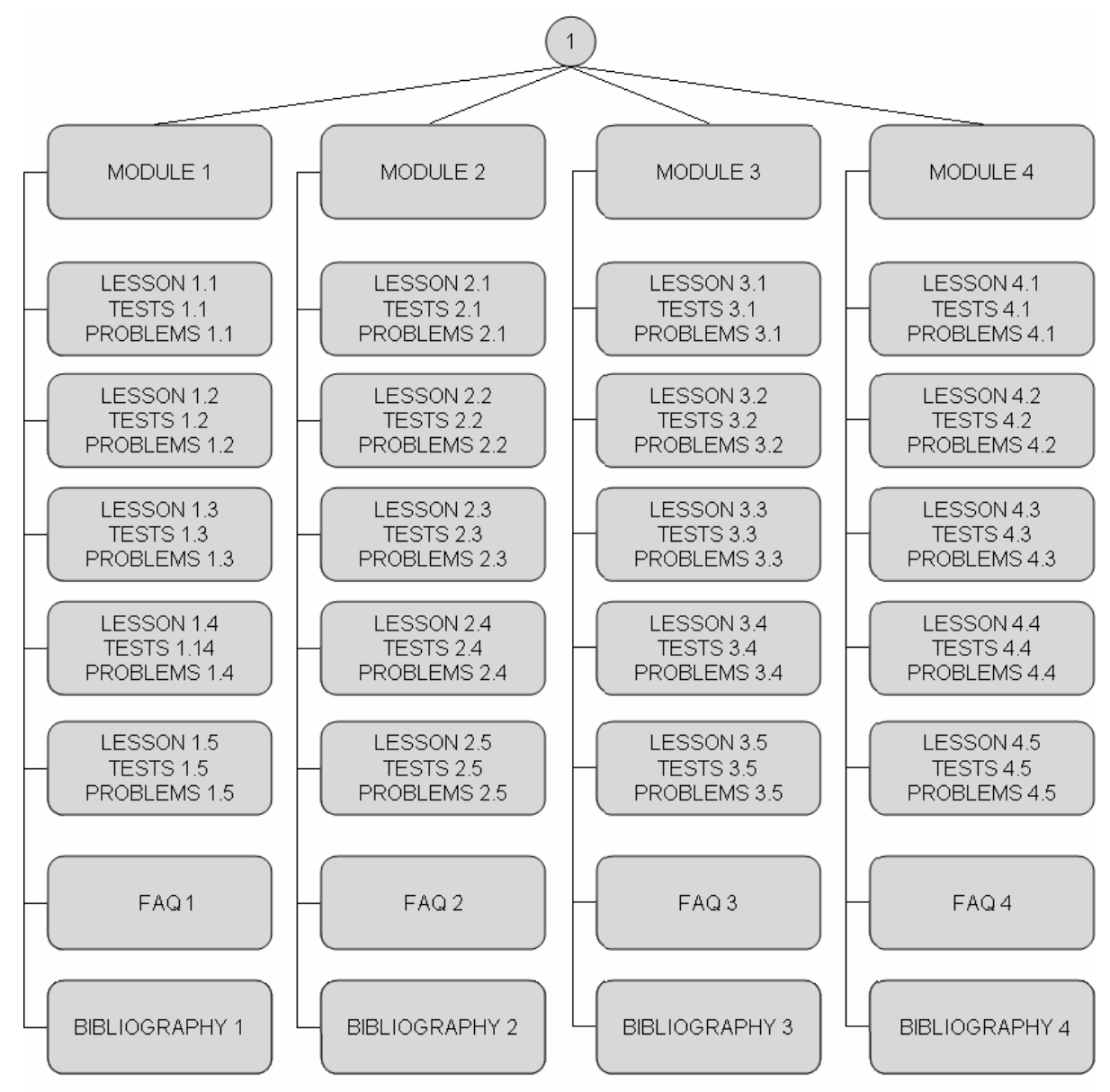

Figure 5. Knowledge thesaurus for learning

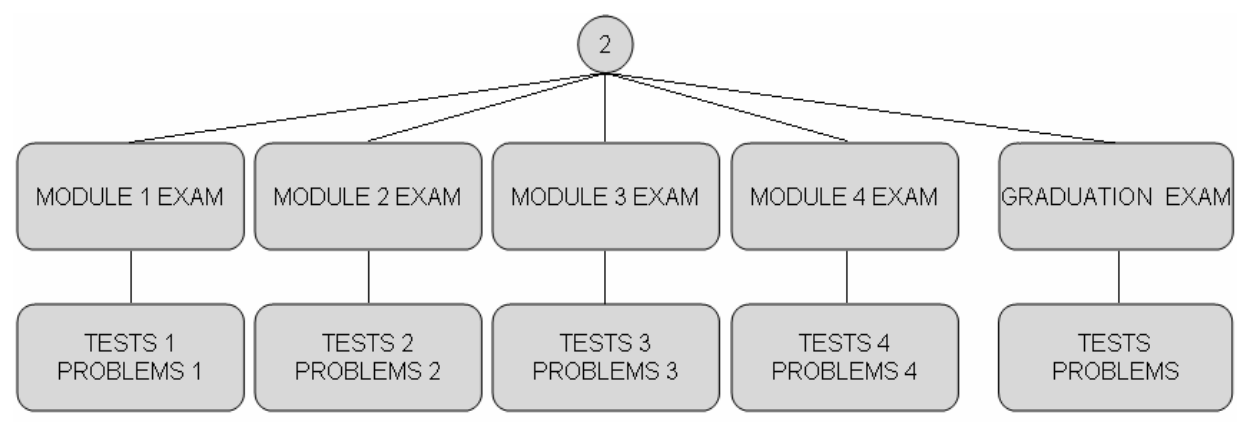

Figure 6. Knowledge thesaurus for verifying

1) Defining the mathematical model. This module presents the MADM mathematical model, which includes structured and unstructured information: decision makers, states of nature, objects, attributes, objects -
The lessons are: History, taxonomy, state-ofthe-art, Generalized model's definition, Modeling methodology, Theoretical results important for modeling, Models examples presented in natural language; 
2) Normalization and solving methods for OCPs. This module presents a procedure for reducing multiple decision makers, multiple states of nature problems to single decision maker, single state of nature problems, as well as a large set of solving methods for this last kind of problem. The lessons are: OCPs generating, Solving methodology, Normalization, Characterizations methods, Evaluation methods;

3) IT for design of MADM software applications. This module covers three levels of technology (design specification, pseudocode, and $\mathrm{C}++$ code) for rapid design and development of MADM software applications. The lessons are: DB design specification, OCPs' design specification, OCPs' appealing, OCPs' running, OCPs' solutions;

4) OPTCHOICE - MADM modelling and solving software $[9,10]$. The last module is a tutorial on the MADM modelling and solving pervasive service (available to anyone on the Internet, free of charge, from any place and at any time). The service uses the software named OPTCHOICE, which covers the needs to define and solve optimal choice problems in the MADM paradigm. The lessons are: Software and hardware platform, Users' registration, About DB using, MADM models editing, OCPs generating, solving and getting solutions.

\section{On line multiple choice tests}

In the framework of generalized MADM model, which elements characterize the states of nature's set?

a) Cod, Name, Description, Relative Importance.

b) Name, Description, Relative Importance.

c) Cod, Description, Relative Importance.

d) Cod, Name, Relative Importance.

e) Cod, Name, Description.

\section{Problems}

An agricultural farm with vegetal production encounters a full process of growing. On its very - owned and, also, on the rented lands, different kinds of crops are cultivated according to the rotation system: wheat, oak, maize etc. The owner decides to buy a new piece of machinery, namely that potentially will allow performing the harvesting works without any rendering services, usually accessible only at the end of the harvesting season. The financial implications of rendering this kind of services in these circumstances deal with large portion of lost production because of the overheating and the transportation cost from the machinery owner and the harvest location. On the other hand, the cost of new piece of machinery may exceed the current cash so that the farm owner decides on buying second-hand machinery but no old than 5 years.

In the selection process, the experts recommend the following characteristics to be reviewed:

1. The cost of the equipment,

2. The gas consumption on a cut down and threshed hectares;

3. Feasibility in functioning,

4. The width of the header.

So, obviously, the cost of the combine and the gas consumption should be as small is possible, and the feasibility in operating and the width of the header to the largest extend. As absolute degree of importance, these attributes have the following values for the farm owner: $40 \%, 30 \%, 20 \%$ and $10 \%$.

Being willing to spend at most 95000 LEI for purchasing the combine, by analyzing the current offers on the market, the owner identifies five possible combines that meet the prerequisites. These possible choices are given as a set of alternatives, noted by $\mathrm{O}$, consisting of elements $o_{1} o_{2 \ldots, \ldots}, o_{5}$, where $5=$ Card O.

According to the attributes expressing requirements, the first two do not raise any understanding problems, being given as follows.

Costs: 90000, 85000, 95000, 75000, 78000 LEI. Consumptions: 36, 35, 32, 40, 35 1/ha.

The next two ask for some explanations:

1) The maintenance property, as requested by actual standards, stipulates that in the harvest season, the equipment is described in one of the following states: position at rest, position 
at repair, position at work with the probabilities: $0.2,0.1$ respectively 0.7 . By studying the register cards about the equipment functioning, and taking into consideration the last three years (because two of the machines only worked three years), the following set of data was set (in conventional days):

- For the position at rest: 20, 15, 32, 30, 18;

- $\quad$ For the non-working position: 5, 7, 8, 8, 7;

- $\quad$ For the working position: 95, 98, 80, 82, 95.

So, the maintenance attribute will be associated with three sub-attributes, namely: position at rest, position at repair, respectively, position at work.

2) The header is the frontal component of the equipment, ensuring the harvesting operation. Even though the width of the header is inversely proportional to the advance speed, the experts establish that, according to the covered surface of threshing, it is more efficient a piece of machinery with a larger header in width as compared to the one with a smaller header. The width figures for the five pieces of machinery are: $5,86,66,45,26,0$ meters.

The attributes set is given by $A$, and its elements are noted with $a_{1}, a_{2}, a_{3}, a_{4}, a_{5}, a_{6}$, where $6=$ card $A$, in which one should regard that the maintenance attribute is represented by three sub-attributes.

Under these conditions, the optimal choice about the machinery is requested.

\section{Most frequent questions}

Which is the main software instruments used in OPTCHOICE development?

The software instruments, minimally enumerated, are: MySQL, PHP, MSVC, Java, Macromedia Dreamweaver MX, Flash MX, Voice, SnageIt.

\section{KT's origin}

The e-course's lessons originate in the book Multiple Attribute Decision Making - Theory and Practice (see Figure 7) written by the first author of this paper. The book, in Romanian, is available on Internet in an electronic library at www.e-librarie.ro, mathematics section, library initiated by the second author. The digital libraries, in the modern view of the concept, permit to any person to access all the human knowledge, anywhere and anytime, in an easy, multimodal and effective manner, overcoming the barriers of geographical distance, language and culture, by using multiple equipments connected to the Internet $[11,12,13]$.

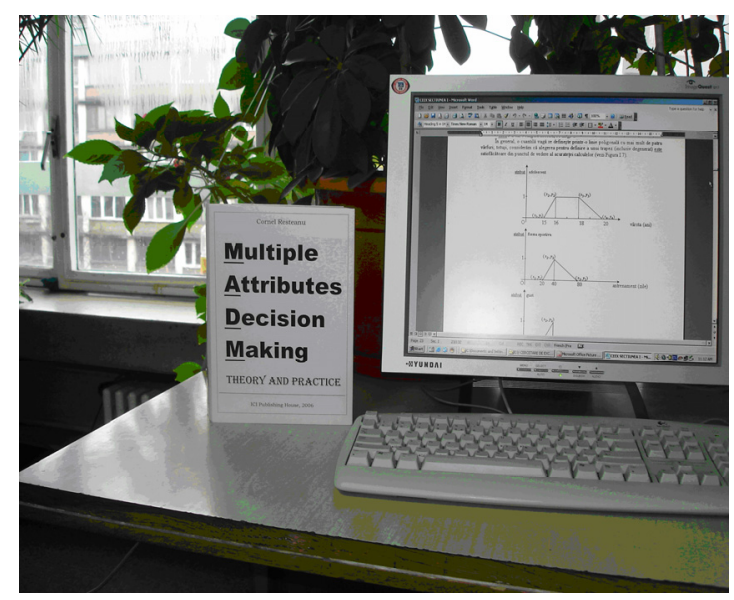

Figure 7. The source of lessons' content

The grill-tests, the problems / case studies and the most frequent questions used in ecourse and e-course's exams originate in the practice of the designing consortium. It was possible because the project benefited from the work of a powerful consortium: National Institute for R\&D in Informatics - Bucharest (two research workers, three programmers and other specialists), University of Bucharest (two professors and three master students as programmers) and Bucharest Academy of Economic Studies (five professors and four students as programmers).

\section{E-Course's General Shell}

The GS is the software part of an e-course. It realizes the e-course functions through the graphical user interface (GUI) between the e-course, as a software system, and the users. It is easy to accept that there are two categories of users: administrators and teachers, and respectively, students and 
visitors. Therefore there are two regimes of functioning: management and utilization.

In the users' and DC management, of paramount importance is the MySQL Data and Knowledge Base (D\&KB) which provides tools to stoke and work with a large amount of information of different types. The GUI beetween users and D\&KB is realized using specific instruments manipulated through the agency of PHP. The D\&KB structure contains entities, and the entities contain fields of various types, importance is the blob type, that can hold .pdf files of large dimensions, as needed in this case.
It is to notice that the first two regions of screen are dedicated to navigation through the functions system and the third region is dedicated to DC displaying.

\section{Users' Management}

The users' management is shown in Figure 8. The access to the e-course facilities is the same for all the type of users. There is a registration procedure that has the role of user profile recording and asking for a user parole. This parole randomly generated by the system and delivered to the user after a

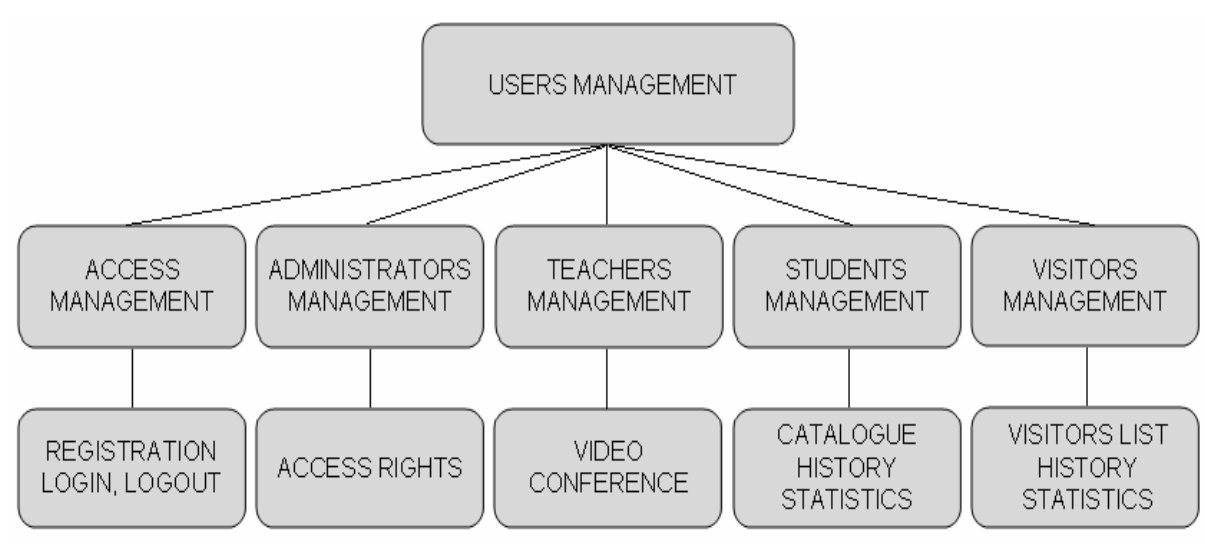

Figure 8. Users' management

In users' management, there is a work with (alpha)numerical information. In the DC's management, there is mostly a work with graphical information. In the learning services, the students only read the D\&KB then is obvious that the GUI, in both situations, will be the same on all nodes of GUI's tree but the leafs' level. In the utilization of some facilities mediated by Internet, the interface is represented by links.

The screen organization is as following:

- On screen's top there is a horizontal strep with the role of navigation over the modules and exams.

- On screen's left side there is a vertical strep with the role of navigation over the learning days into a module. On the same strep one displays the MK.

- The rest of the screen is dedicated to the displaying the leafs' level of GUI. short verification of user's seriousness may be changed as other user's information using the modify profile procedure. The registration procedure, completed with the login and logout procedures, assures the access into the system with preserving the security requirements.

The administrators' management contains two functions. The first function refers to the main administrator and provides to him, after the software installing, a pre-created profile registration that must be filled with personal identification data. The second function refers to the main administrator's possibility to grant rights to the rest of administrators regarding students / visitors and digital content management.

The teachers, after registration, organized as e-course's council, can talk about the ecourse's necessities and decide in all problems that appeared. This is possible through the e-course's video-conference. 
For students / visitors, the administrators can provide catalogue / list, the history files, containing the graduate or renouncing students / visitors, and some statistics. For students, after graduation, the diploma are edited and sent to them in due time. problems / case studies set in such a way that the collisions, in a long period of time, to be avoided. A direct approach of this problem, without any precaution, has a serious drawback: when a large number of students located in different parts of the world take exams, the

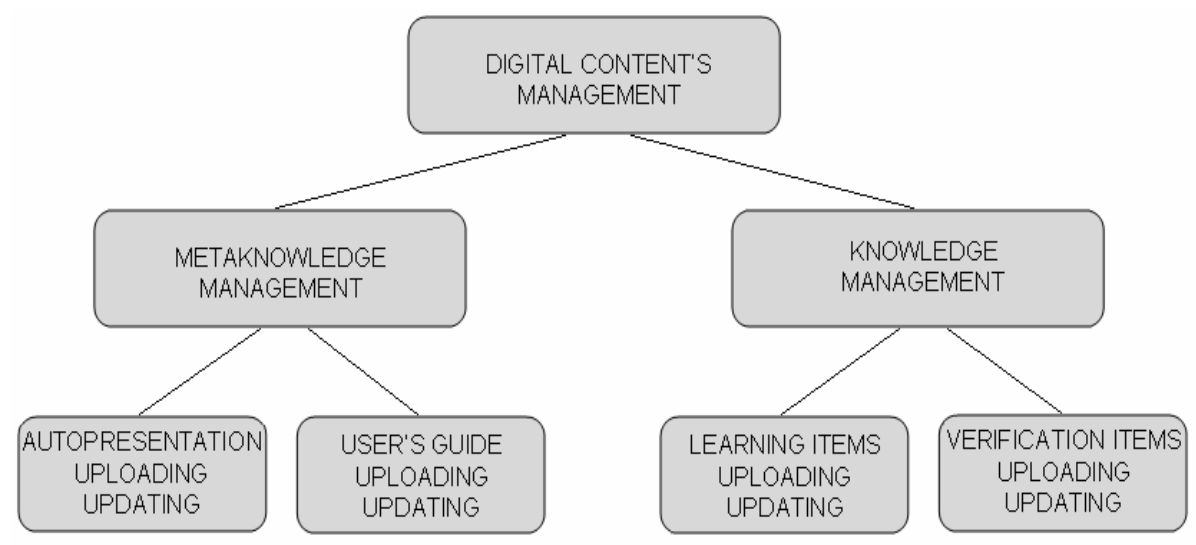

Figure 9. Digital content's management

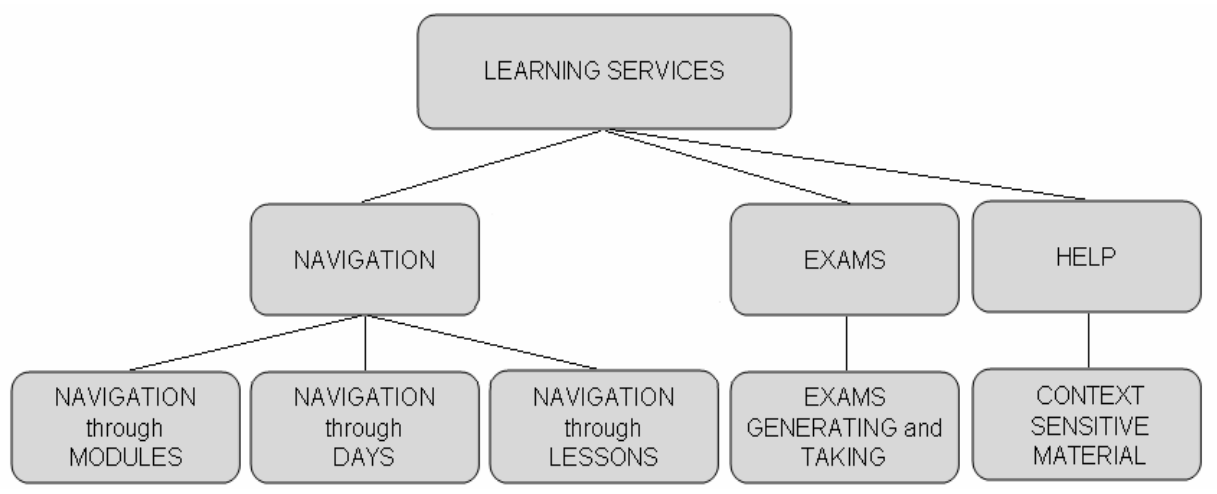

Figure 10. E-course's learning services

\section{Digital Content's Management}

As said above, the administrators must have continuously the control on DC through the agency of GS. The D\&KB's loading and updating (see Figure 9) refers to the autopresentation, users' guide, lessons, grill-tests and problems / case studies (for learning and exams) and most frequent questions. In this e-course, DC initially is loaded in .pdf files. Obviously, GS can work directly with these files but in this case the DC's security is in big danger. Therefore the D\&KB is necessary. This manner, DC is hidden and on disk is visible only one file representing the D\&KB. A special administration function is the exams generation. In order to avoid certain possible fraud methods specific to electronicformat exams, it is essential that each exam to be randomly generated from the tests and response time to the query of generating new exams can be large enough to become frustrating for some of the students. Using mechanisms of planning the inputs crowding in the system (i.e. the queries of generating exams) and releasing the outputs from the system (i.e. the exams completion by students), a Monte Carlo algorithm prompts the administrators when to enrich the tests and problems / case studies sets, and also indirectly shows the necessary volume in each category. The Monte Carlo algorithm is not a simulation, but it is running at warm, because it generates exams.

\section{Learning Services}

GS in using means learning and verification on GS base (see Figure 10). The students are expected to learn how to solve decision problems. 
After positioning on a module and a day, the student may read the corresponding lesson and solve the associated grill-tests and problems / case studies. The problems may be solved either by hand or by using the OPTCHOICE software. However, an indication of the success of the authors' efforts in this course is when the students are capable to use proficiently the OPTCHOICE software. A very good help in learning is the consulting the most frequent questions. It is possible to ask questions and get answers as well. The modules of the e-course can only be approached sequentially, following the order established by design, so that a higherorder module becomes available only after passing the exam given at the end of the preceding module. At the beginning, the natural ranking of module and days must be respected but arrived at a given module-day, it is possible to access any module-day with smaller rang.

\section{Mediation Services}

The e-course works on Internet. Therefore it is possible to maintain a rapid dialog with ecourse officials and to have a direct access to ICI's site and e-course forum. This kind of services is named mediation services (see Figure 11).

The first type of services help the students to have access to the e-course's administrators, tutors and scientific council:

- The link to administrators may be necessary in the cases of administrative problems (initial paroles, payments, sending diploma etc.).

- $\quad$ - The link to tutors is obviously necessary because, during the learning process, it is normal to ask questions to the expert persons in the field.

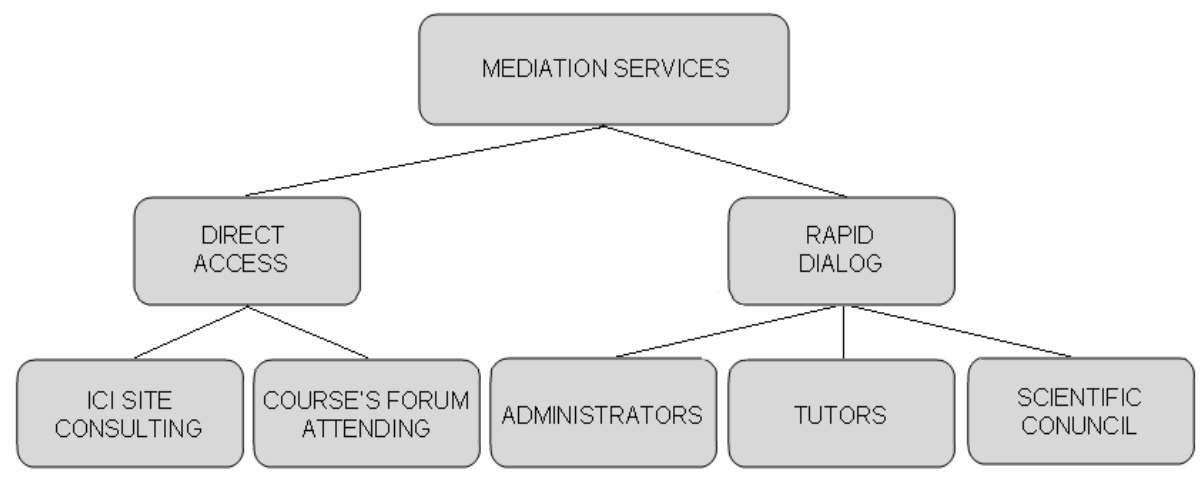

Figure 11. E-course's mediation services

The course is successfully completed when passing a graduation exam, which can only be taken after passing the five end-of-module exams. An end-of-module exam consists of 10 randomly selected tests, meaning 2 from each learning day, and one problem / case study. The graduation exam has the same structure.

Every exam can be interrupted on grill-tests three times and on problems / case studies also three times. The break must be less than 24 hours. It is to say that, in this case, the last exam item do not reappears at resuming. The e-course graduation is on 3 levels: beginner, professional and expert.
- - If the students' questions refer to the ecourse quality or the students can bring improvements, then the link to scientific council is welcome.

- The second type of services offers:

- - The ICI's site, where the students can find out a large set of software that may be of interest to them.

- - The e-course's forum, where to the students and visitors have the possibility to learn from the common experience.

If these mediation services are not integrated in the e-course software, the students' effort to be linked to the natural e-course environment becomes very difficult to make. 


\section{Conclusions}

The MADM e-course opened a new way in the instrumentation of LLL, producing a significant example (see Figure 12).

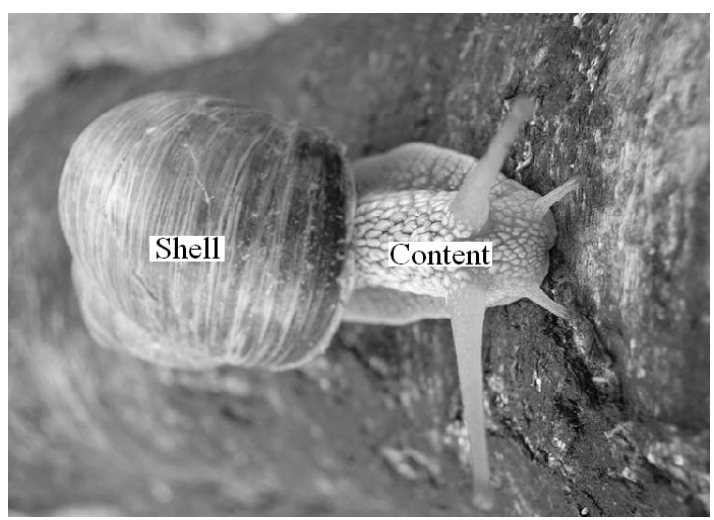

Figure 12. An e-course is content into a shell

The service „Do learn by yourself MADM!”, Romanian version, runs as a experimental system, on powerful computers, at ICI. An English version is now in progress and will be presented as Internet service in one year. The endowment equipment, i.e. powerful servers, will be enough to assure technical performance for this service that will be open world wide.

The main gain from this research in the ecourses field is the technological results broadly presented in the paper. A general shell capable to be filled-in with diferent digital content is a very good tool to generate e-courses. The e-course generation's time depends only on the capability to structure the domain material according to the general shell's requirements.

An e-course developed by this technology is easy to maintain and utilize, having all characteristics that may be demanded from a modern e-learning service.

\section{REFERENCES}

1. HWANG, C-L., K. YOON, Multiple Attribute Decision Making. SpringerVerlag, Berlin-Heidelberg, New York, 1981.

2. HWANG, C-L., M. J LIN, Group Decision Making under Multiple Criteria, Springer-Verlag Berlin Heidelberg, New York, 1997.
3. http://europa.eu.int/comm/education/poli cies/2010/et_2010_en.html.

4. RUMBLE, G., Reinventing Distance Education, 1971-2001. Intl. Journal of Lifelong Education, 20, 2001, pp. 31-43.

5. ThORSTEInSSON, G., T. PAGE, A. NICULESCU, A Blended Learning Approach to Enhancing Innovation, Studies in Informatics and Control, vol. 17(3), 2008, pp. 297-304.

6. THORSTEINSSON, G., T. PAGE, A. NICULESCU, Adoption of ICT in Supporting Ideation Skills in Conventional Classroom Settings, Studies in Informatics and Control, vol. 19(3), 2010, pp. 309-318.

7. RESTEANU, C., F. G. FILIP, C. IONESCU, M. SOMODI, On Optimal Choice Problem Solving, Proc. SMC'96 Congress (Beijing, Oct. 14-17). A.P. Sage, W. Zheng (Eds.), IEEE Publising House, Piscataway, 1996, pp. 1864-1869.

8. GIARRATANO, J. C., G. D. RILEY, Expert Systems: Principles and Programming - 3rd ed. PWS Publishing Company, Boston, 1999.

9. http://www.nottingham.ac.uk/teaching/re sources/methods/elearning/mathemat519/

10. http://www.wordreference.com/definition /pervasive

11. BANCIU, D., Digital Libraries from Concept to Practice, Contributions to ICT Progress, Technical Publishing House, Bucharest, 2007, pp. 77-93.

12. BANCIU, D., ALBU, C., The Role of the e-Book in Learning Process, Proc. 2nd Balkan Reg. Conf. on Eng. Edu., (Sept. 16-19, 2003 Sibiu, Romania), pp. 183-184.

13. SEBESTYEN, G., D. BANCIU, T. BALINT et al., Digital Content Management on GRID Structures, Proc. Conf. Information: IEEE 3rd Intl. Conf. on Intelligent Computer Comm. and Processing. (Sept. 06-08, 2007 ClujNapoca, Romania), pp. 259-262. 